\title{
Metallic Niobium Powder Reduced by Atmospheric Magnesium Gas with Niobium Pentoxide Powder
}

\author{
Su-Jin Park ${ }^{1,2}$, Seon-Min Hwang ${ }^{1,2}$, Jei-pil Wang ${ }^{3}$, Young-Guk Son ${ }^{2, *}$ and Dong-Won Lee ${ }^{1, *}$ \\ ${ }^{1}$ Korea Institute of Materials Science (KIMS), 797, Changwondaero, Seongsan-gu, Changwon, Gyeongnam 641-010, Korea \\ ${ }^{2}$ Department of Materials Science and Engineering, Pusan National University, 2, Busandaehak-ro 63 Beon-gil, Geumjeong-gu, \\ Busan 46241, Korea \\ ${ }^{3}$ Department of Metallurgical Engineering, Pukyong National University, 45, Yongso-ro, Nam-gu, Busan 48513, Korea
}

\begin{abstract}
It was tried to find the optimal condition to prepare the metallic niobium powder with minimal oxygen content by atmospheric magnesiumgas reduction of niobium pentoxide $\left(\mathrm{Nb}_{2} \mathrm{O}_{5}\right)$ powder at $1073-1223 \mathrm{~K}$, which are industrially moderate and low temperature ranges until maximally $80 \mathrm{~h}$ inside the chamber held under the argon circumstances of $110 \mathrm{kPa}$. Magnesium oxide of the by-product of the reduction, was dissolved and removed fully by dissolving in a $10 \%$ aqueous hydrochloric acid solution. The particle size of the niobium powder reduced for $20 \mathrm{~h}$ was slightly increased within the range of $200 \sim 600 \mathrm{~nm}$ according to increase of reduction temperatures. And such fine particles were further coarsened to near $1 \mu \mathrm{m}$ by increase of reduction times until $80 \mathrm{~h}$ at $1173 \mathrm{~K}$, which is thought to be the most suitable for magnesium-gas reduction to be applied in industry. The reduction time satisfied for a maximal reduction effect was found to be 60 hours as the oxygen content was then minimally saturated to about $0.42 \mathrm{wt}$. $\%$. Furthermore, the hydrogen contamination due to acid leaching of 0.28 wt. $\%$ was fully removed by dehydrogenation, which was a heat treatment performed under vacuum at $827 \mathrm{~K}$ for $2 \mathrm{~h}$; this resulted in the formation of metallic niobium powder. [doi:10.2320/matertrans.MT-M2020241]
\end{abstract}

(Received July 27, 2020; Accepted October 7, 2020; Published November 20, 2020)

Keywords: niobium powder, magnesium reduction, niobium pentoxide powder, magnesium oxide, hydrochloric acid solution, niobium hydride

\section{Introduction}

Metallic niobium has been used as an alloying element for producing titanium-based jet engine alloys and nickel-based superalloys owing to its high melting point $(2740 \mathrm{~K})$ and excellent ductility and malleability. Its high electrical conductivity allows it to be widely used in the electronics industry, especially in electrodes of capacitors. ${ }^{1)}$ Therefore, research focused on the extraction of high-purity niobium $(\mathrm{Nb})$ is important.

In the current commercialized niobium extraction process, $\mathrm{Nb}$-containing raw ore is first treated with hydrofluoric acid to produce niobium pentoxide $\left(\mathrm{Nb}_{2} \mathrm{O}_{5}\right)$ of normal purity. ${ }^{2)}$ Subsequently, it is reduced to its metal form using metallic reducing agents such as calcium, sodium, aluminum, and magnesium.

In the case of calcium reduction, the process is performed usually at approximately $1273 \mathrm{~K}$, the by-product calcium oxide $(\mathrm{CaO})$ can be easily removed. However, caution must be exercised while handling metallic calcium at high temperatures because it has a high affinity to oxygen and poses a risk of ignition. ${ }^{3,4)}$

When sodium is used as a reducing agent, the reduction temperature is low, which is favorable to produce niobium powder with fine crystals. Additionally, it is easy to remove the by-product sodium oxide $\left.\left(\mathrm{Na}_{2} \mathrm{O}\right) .{ }^{5,6}\right)$ However, as with calcium reduction, there is a high risk of ignition if the sodium is exposed to oxygen at high temperatures.

In aluminum reducer, aluminum oxide $\left(\mathrm{Al}_{2} \mathrm{O}_{3}\right)$ is formed as a reduction by-product. Although the agent is favorable at high temperatures and for mass production, it is difficult to remove the $\mathrm{Al}_{2} \mathrm{O}_{3}$ mixed with the product and easily contaminated by undesired aluminum content. ${ }^{7,8)}$

*Corresponding authors, E-mail: ykson@pusan.ac.kr, ldw1623@kims.re. $\mathrm{kr}$
Also, some studies reported reducing $\mathrm{Nb}_{2} \mathrm{O}_{5}$ with silicon. In this process, niobium silicide $\left(\mathrm{NbSi}_{2}\right)$ can be formed as an intermediate compound during the reduction, because silicon is soluble in solid niobium. This intermediate compound does not dissolve well in acid solutions with silicon dioxide $\left(\mathrm{SiO}_{2}\right)$. This renders it difficult to recover pure niobium. ${ }^{9)}$

When magnesium is used as the reducing agent, the operating temperature is relatively low normally below $1223 \mathrm{~K}$, and there is no mutual solid solubility between magnesium and niobium up to $1723 \mathrm{~K}$. Therefore, only pure niobium and the by-product magnesium oxide $(\mathrm{MgO})$ are present after the reduction. As $\mathrm{MgO}$ can be easily removed by dissolving well in weak aqueous hydrochloric acid $(\mathrm{HCl})$ solutions, the extraction of pure niobium can be performed efficiently. All of solid powder, liquid and gas phase of magnesium are possible to be applied as reduction agents. However, when the liquid magnesium contacts $\mathrm{Nb}_{2} \mathrm{O}_{5}$ powder directly, it may be resulted in rapid, violent and explosive behavior. ${ }^{10)}$ Hence there is a research case of the reduction reaction induced slowly by mixing and molding powdered magnesium with niobium oxide. ${ }^{11,12)}$ However there is a risk as using explosive or relatively expensive magnesium powder.

A group of researchers recently used evaporated magnesium gas to allow a slower reaction with niobium oxide. This method avoids the use of magnesium metal powder and the potential for a rapid and violent reaction involving liquid magnesium and, hence, induces the reduction more economically and safely. The authors of the study had previously conducted research on the reduction of vanadium oxide $\left(\mathrm{V}_{2} \mathrm{O}_{5}\right)$ and tantalum oxide $\left(\mathrm{Ta}_{2} \mathrm{O}_{5}\right)$ for this purpose. ${ }^{13,14)}$

And, the previous works on the reduction of niobiumbased oxide by magnesium gas have been reported but they used not pure $\mathrm{Nb}_{2} \mathrm{O}_{5}$ but $\mathrm{Mg}_{4} \mathrm{Nb}_{2} \mathrm{O}_{9}$ as start material and 
fixed reduction temperature. ${ }^{11,15-17)}$ And it could be found the research work on the magnesium gas reduction of pure $\mathrm{Nb}_{2} \mathrm{O}_{5}$ with various reduction temperatures and times, ${ }^{15)}$ it was employed the sintered $\mathrm{Nb}_{2} \mathrm{O}_{5}$ preform as start material and pressured magnesium gas by welded so isolated chamber, which structures may be difficult to be commercialized. Actually in a reactor chamber made of stainless steel to be operated in elevated temperatures, to keep and control the inner chamber pressure to near atmospheric pressure is largely advantageous due to lifetime enhancement of chamber and for mass-production.

Therefore, this study aimed to perform the reduction reaction of pure niobium oxide powder by magnesium gas of near atmosphere pressure with changing the reaction temperatures and times to find the optimal condition for reduced niobium metal powder to have minimal oxygen content.

\section{Experimental Procedures}

Pure niobium oxide powder (99.99\%, Jiujiang Ltd., China) was used as the initial compound for magnesium reduction. Considering the molar amounts of the reactants for the reduction reaction $\left(\mathrm{Nb}_{2} \mathrm{O}_{5}+5 \mathrm{Mg} \rightarrow 2 \mathrm{Nb}+5 \mathrm{MgO}\right)$, the ratio of the mass of $\mathrm{Nb}_{2} \mathrm{O}_{5}$ to that of $\mathrm{Mg}$ should be 266:120. In this study, $100 \mathrm{~g}$ of $\mathrm{Nb}_{2} \mathrm{O}_{5}$ powder was used, which means the theoretical amount of $\mathrm{Mg}$ required for reduction is $45 \mathrm{~g}$.

However, for a sufficient reduction reaction, $150 \mathrm{~g}$ of $\mathrm{Mg}$ was used, providing an excess of $\mathrm{Mg}$. The prepared $\mathrm{Nb}_{2} \mathrm{O}_{5}$ powder and magnesium pieces were placed in a stainlesssteel reactor using a graphite crucible, as shown in Fig. 1. A vacuum pressure of $6 \times 10^{-4} \mathrm{kPa}$ was applied using a rotary vacuum pump, and we injected $99.999 \%$ pure argon until atmospheric pressure was reached. This process of vacuum and argon treatments was repeated three times. Finally, the temperature was increased to $1073 \mathrm{~K}, 1123 \mathrm{~K}$, $1173 \mathrm{~K}$, and $1223 \mathrm{~K}$ in different iterations with the heating rate, $10 \mathrm{~K} / \mathrm{min}$. In all cycles during reduction reaction, the chamber pressure was kept in the rage of $105 \sim 115 \mathrm{kPa}$ by auto-control of vent and argon-in. And such condition was continued during furnace cooling to room temperature. As traces of nitrogen in the chamber may contaminate the niobium during reduction, approximately the totally $50 \mathrm{~g}$ of several titanium sponge pieces were also charged into the reactor to remove the nitrogen.

The product $\mathrm{Nb}$ and the by-product $\mathrm{MgO}$ were obtained through the reaction between the niobium oxide and the magnesium gas. X-ray analysis was conducted to examine whether their states had formed well. Afterwards, to obtain the required $\mathrm{Nb}$ only, the $\mathrm{MgO}$ was removed by performing an agitator-induced flushing twice in a $10 \% \mathrm{HCl}$ aqueous solution and three times in distilled water. During the flushing process, it was found that some of the metallic $\mathrm{Nb}$ had changed into niobium hydride $(\mathrm{NbH})$ through a reaction with hydrogen ions. Therefore, metallic $\mathrm{Nb}$ powder was finally obtained by performing a dehydrogenation heat treatment for the removal of the hydrogen component contained in the produced powder at $973 \mathrm{~K}$ and a vacuum pressure of $6 \times 10^{-6} \mathrm{kPa}$ for $2 \mathrm{~h}^{18)}$

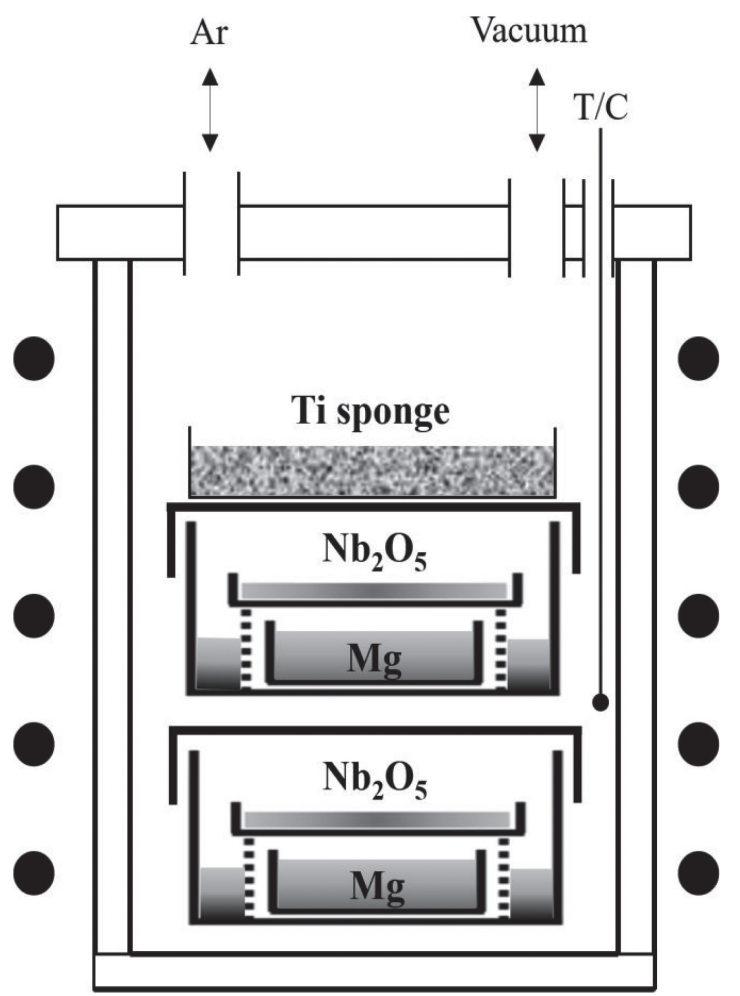

Fig. 1 Schematic structure of the reactor for $\mathrm{Mg}$ reduction of $\mathrm{Nb}_{2} \mathrm{O}_{5}$ powder.

The structure, phase, and components of the obtained metallic $\mathrm{Nb}$ powder were investigated using a scanning electron microscope (MIRA3 LM, TESCAN, Brno, Czech), an X-ray diffractometer (Rigaku, Tokyo, Japan), an oxygen/ nitrogen/hydrogen determinator (ELTRA ONH-P, Haan, Germany), a transmission electron microscope (JEOL 2100F, JEOL Ltd, Tokyo, Japan), and an elemental analyzer (Flash 2000, Thermo Fisher Scientific, U.K.).

\section{Results and Discussion}

Figure 2 shows the scanning electron microscope image of the niobium oxide powder used as the initial raw material.

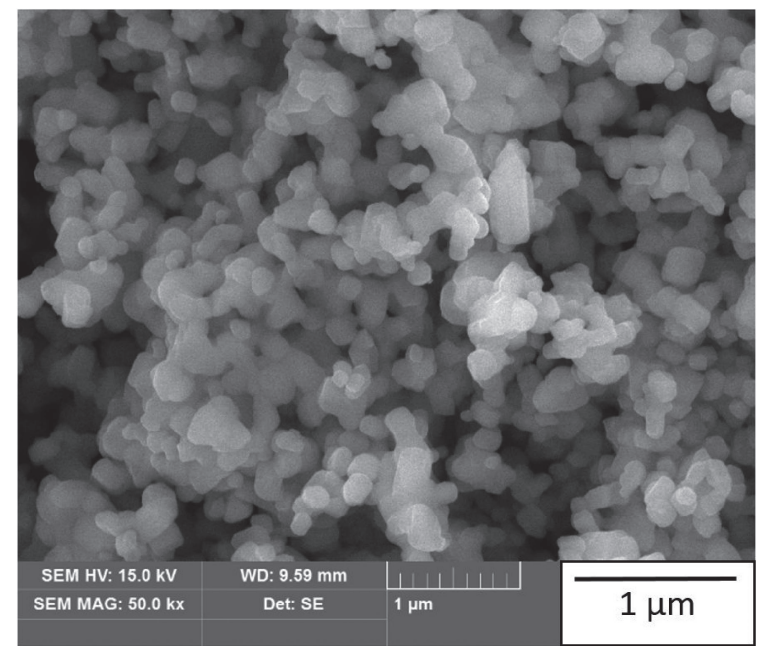

Fig. 2 SEM microstructure of the initial $\mathrm{Nb}_{2} \mathrm{O}_{5}$ powder for $\mathrm{Mg}$ reduction. 


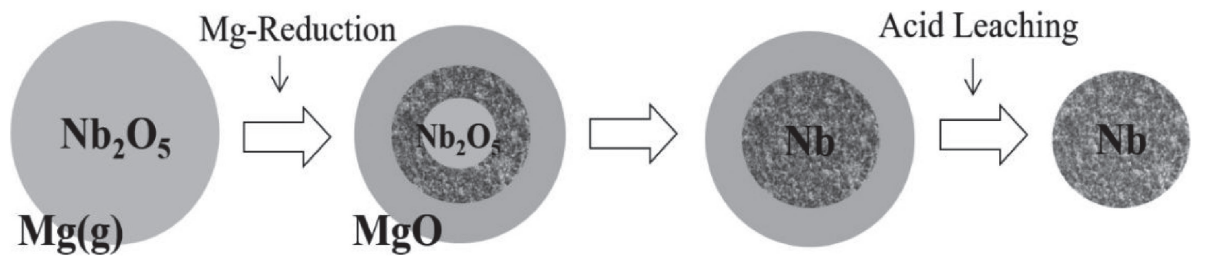

Fig. 3 Schematic concept of reduction behavior from $\mathrm{Nb}_{2} \mathrm{O}_{5}$ to $\mathrm{Nb}$ by magnesium gas.

The particle size was found to be approximately $200 \mathrm{~nm}$, and the niobium oxide phase was confirmed by the X-ray diffraction analysis results.

Figure 3 is a schematic of the magnesium reduction reaction of niobium oxide. The free energy change for the reduction reaction in the range of 1073-1223 K indicates that the reaction driving force is sufficiently large, as shown in the following equation:

$$
\begin{aligned}
& \mathrm{Nb}_{2} \mathrm{O}_{5}(\mathrm{~s})+5 \mathrm{Mg}(\mathrm{g}) \rightarrow 2 \mathrm{Nb}(\mathrm{s})+5 \mathrm{MgO}(\mathrm{s}) \\
& \Delta \mathrm{G}_{1073 \mathrm{~K} \sim 1223 \mathrm{~K}}=-993 \sim-969 \mathrm{~kJ} / \mathrm{mol}
\end{aligned}
$$

Reduction begins at the surface of the $\mathrm{Nb}_{2} \mathrm{O}_{5}$ particles through the reaction with magnesium gas, forming a $\mathrm{MgO}$ film on the surface of the particles. Hence, reduction occurs when oxygen is diffused from the inside of the particles to the surface. As this reaction continues, the formation of metallic $\mathrm{Nb}$ inside the particles is eventually completed. Upon the completion of the reduction, pure $\mathrm{Nb}$ can be obtained by stirring the powder in aqueous $\mathrm{HCl}$ solution to remove the $\mathrm{MgO}$ formed on the surface.

It was presented representatively in Fig. 4 the SEM image and X-ray diffraction pattern of the powder reduced for $20 \mathrm{~h}$ at $1173 \mathrm{~K}$ because operation was relatively difficult when the reduction temperature was as high as $1223 \mathrm{~K}$, due to the rapid vaporization of magnesium. The X-ray diffraction results in Fig. 4(b) show that only $\mathrm{Nb}$ and $\mathrm{MgO}$ phases are present and no $\mathrm{Nb}_{2} \mathrm{O}_{5}$ phase is visible, indicating that the reduction reaction was performed well. In addition, Fig. 4(a) shows that the particle size is several micrometers, and the fine particles adsorbed on the surface appear to be the $\mathrm{MgO}$ formed by reduction, which is currently under investigation.

Figure 5 shows the SEM image and X-ray diffraction analysis of the $\mathrm{Nb}$ powder, obtained by washing the $\mathrm{Nb}$ and $\mathrm{MgO}$ composite phase powder, reduced at $1173 \mathrm{~K}$ in a $10 \%$ $\mathrm{HCl}$ aqueous solution to remove the $\mathrm{MgO}$ components. Figure 5(a) shows that the particle size is between 100 and $200 \mathrm{~nm}$, which is similar to the particle size of the initial material shown in Fig. 2. It appears that the particles of the reduced metallic $\mathrm{Nb}$ powder remain fine because the reduction temperature applied in this study $(1173 \mathrm{~K})$ is significantly lower than the melting point of $\mathrm{Nb}(2740 \mathrm{~K})$ and, thus, the particles do not significantly grow after nucleation. Figure 5(b) shows that metallic $\mathrm{Nb}$ is formed well, but the niobium hydride phases an amount of about $30 \%$ are also mixed because the metallic $\mathrm{Nb}$ powder reacted with hydrogen ions during the stirring in aqueous $\mathrm{HCl}$ solution.

The $\mathrm{MgO}$ and magnesium removal reactions in aqueous $\mathrm{HCl}$ solution were attributed to the formation of $\mathrm{MgCl}_{2}$, and the reaction equations can be expressed as follows:
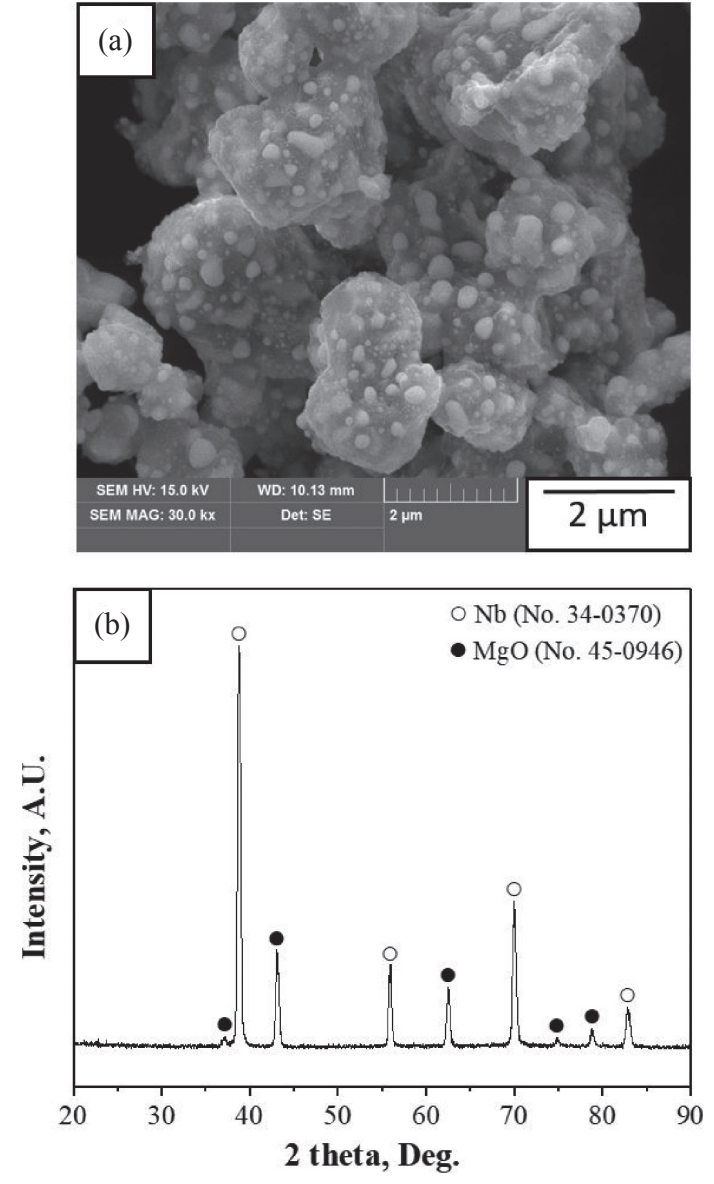

Fig. 4 SEM microstructure (a) and X-ray diffraction pattern (b) of Mgreduced powder at $1173 \mathrm{~K}$ for $20 \mathrm{~h}$ before acid leaching.

$$
\mathrm{MgO}+2 \mathrm{HCl} \rightarrow \mathrm{MgCl}_{2}+\mathrm{H}_{2} \mathrm{O} \quad \Delta \mathrm{G}_{300 \mathrm{~K}}=-61 \mathrm{~kJ} / \mathrm{mol}
$$

$\mathrm{Mg}+2 \mathrm{HCl} \rightarrow \mathrm{MgCl}_{2}+\mathrm{H}_{2} \quad \Delta \mathrm{G}_{300 \mathrm{~K}}=-401 \mathrm{~kJ} / \mathrm{mol}$

Figure 6 shows the SEM images of the metallic $\mathrm{Nb}$ powder samples produced at all the reduction temperatures (1073-1223 K) obtained after removing the $\mathrm{MgO}$ from the powder. The particle size shows a tendency to increase from 200-600 nm due to the rise in reduction temperature. Although the particle size was $200-600 \mathrm{~nm}$ as shown in Fig. 6, it was necessary to examine the crystal size inside the $\mathrm{Nb}$ nanoparticles to determine whether these particles were composed of single crystals or polycrystals. The average crystal size was determined using the half-value breadth obtained from the X-ray diffraction analysis and the Scherrer equation $(\mathrm{D}=\mathrm{K} \cdot \lambda / \beta \cdot \cos \theta) .{ }^{19)}$ The Scherrer equation applied the first peak of the X-ray diffraction line for each reduction temperature. $\mathrm{K}$ was the dimensionless shape factor, $\beta$ was the diffraction peak, $\lambda$ was $1.54 \AA$, and $\theta$ was the 

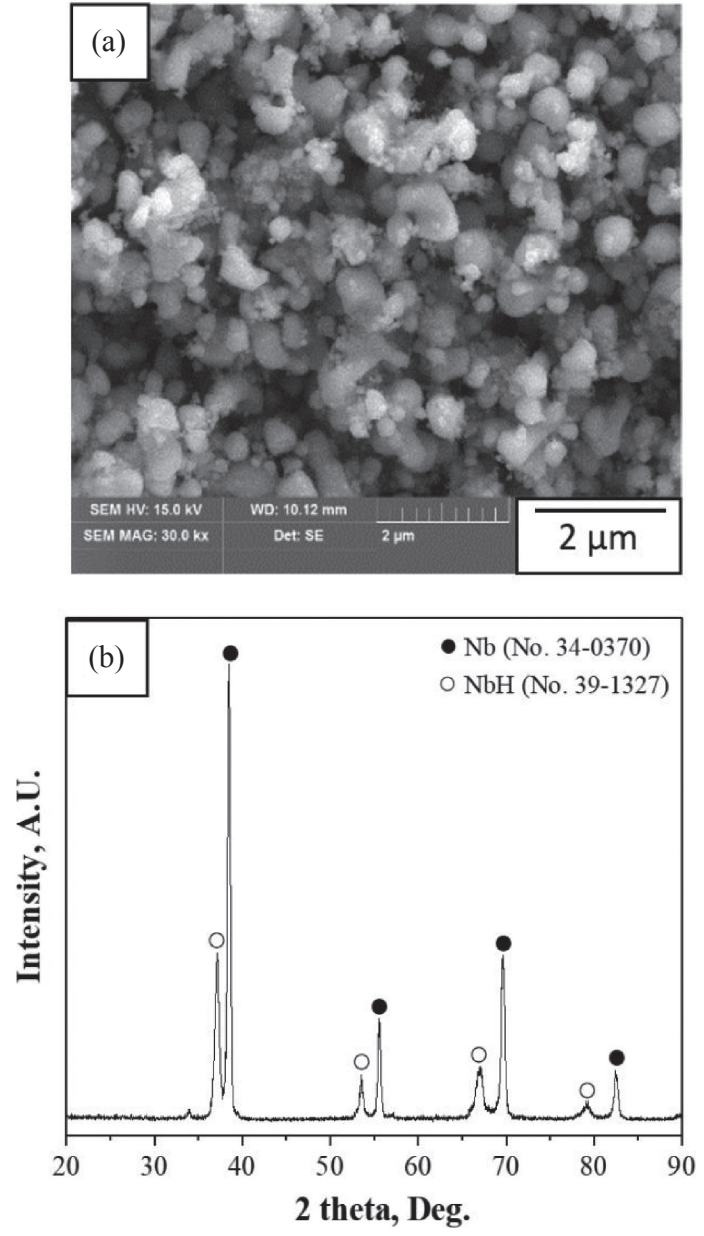

Fig. 5 SEM microstructure (a) and X-ray diffraction pattern (b) of Mgreduced $\mathrm{Nb}$ powder at $1173 \mathrm{~K}$ for $20 \mathrm{~h}$ after acid leaching. diffraction angle. The average crystal size was calculated to be between 25 and $35 \mathrm{~nm}$, which was 10 to 20 times smaller than the particle size observed in the SEM images in Fig. 6. This showed that very fine internal crystal grains were formed because the crystal growth was not substantial, as a result of the low reduction temperature as mentioned before.

Figure 7 shows the results of the X-ray diffraction analysis of the metallic $\mathrm{Nb}$ powder samples produced at all the reduction temperatures. Pure $\mathrm{Nb}$ peaks formed well in all cases, and the $\mathrm{NbH}$ phase is also partially formed in all the

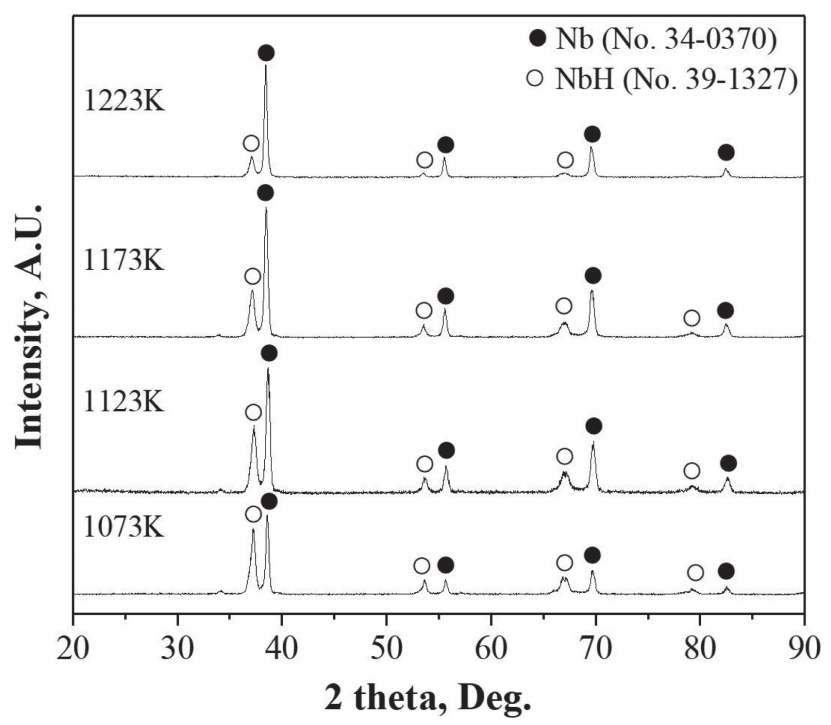

Fig. 7 X-ray diffraction patterns observed in samples of Mg-reduced $\mathrm{Nb}$ powder at different reduction temperatures after acid leaching.
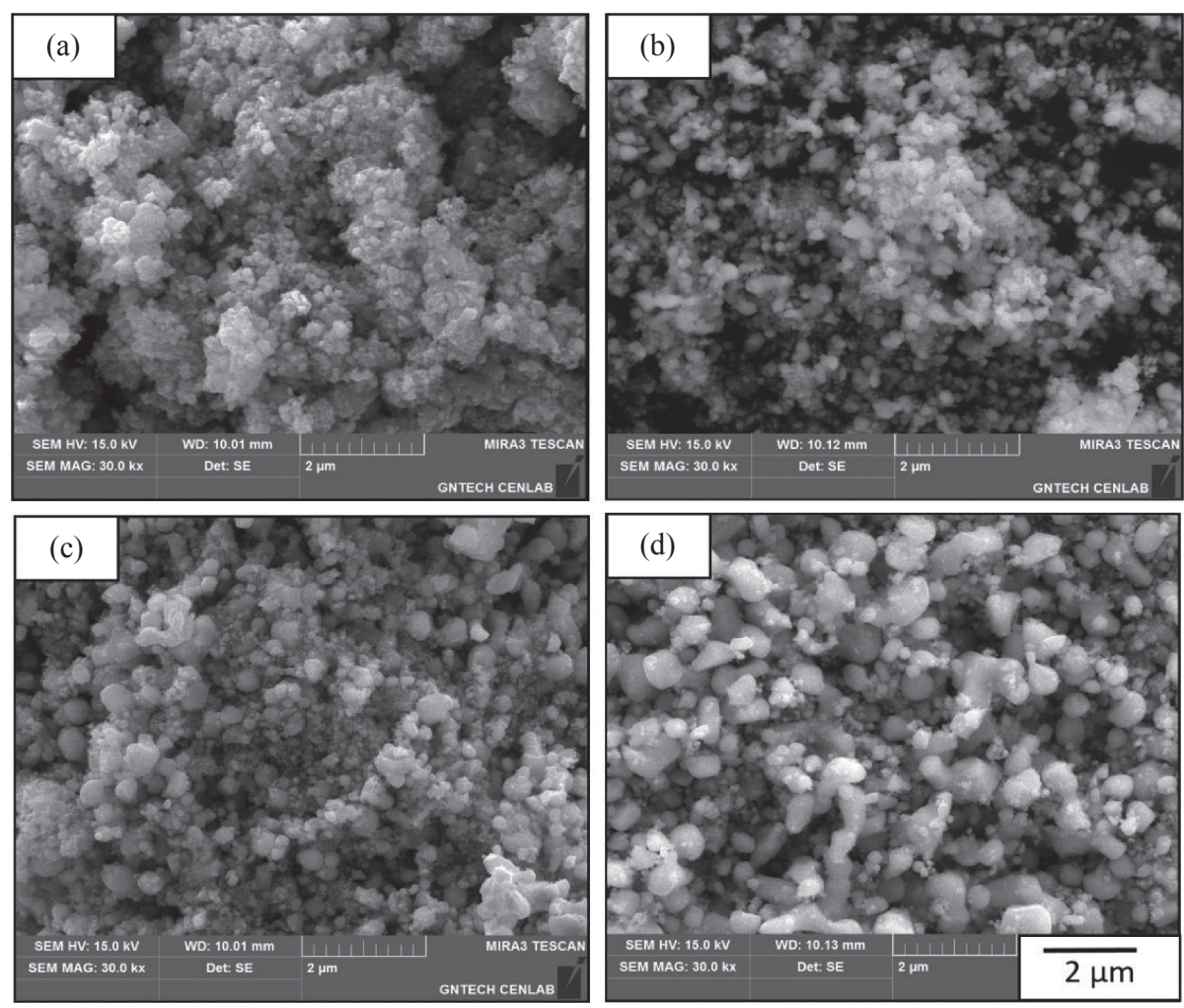

Fig. 6 SEM microstructures of Mg-reduced $\mathrm{Nb}$ powder at different reduction temperatures, $1073 \mathrm{~K}$ (a), $1123 \mathrm{~K}$ (b), $1173 \mathrm{~K}$ (c), and $1223 \mathrm{~K}$ (d) for $20 \mathrm{~h}$ after acid leaching. 
samples due to stirring in the aqueous $\mathrm{HCl}$ solution. The X-ray diffraction intensities for the $\mathrm{NbH}$ phase show that the formation of $\mathrm{NbH}$ increased as the reduction temperature decreased. Quantitatively, this was confirmed by hydrogen analysis, which revealed $0.20 \mathrm{wt} . \%$ at $1223 \mathrm{~K}, 0.28 \mathrm{wt} . \%$ at $1173 \mathrm{~K}, 0.36 \mathrm{wt} . \%$ at $1123 \mathrm{~K}$, and $0.46 \mathrm{wt} \%$ at $1073 \mathrm{~K}$. From these hydrogen contents, we knew that the weight fractions of mixed niobium hydrides corresponded to those from $20 \mathrm{wt} . \%$ to $45 \mathrm{wt} . \%$. The decrease in reduction temperature appears to increase the amount of the $\mathrm{NbH}$ phase, as the finer $\mathrm{Nb}$ particles obtained during reduction at lower temperatures led to higher reactivity with hydrogen ions in the aqueous $\mathrm{HCl}$ solution.

The X-ray diffraction analysis results in Fig. 7 show no oxide phase, but an oxygen analysis revealed high oxygen concentrations, which were $23.2 \mathrm{wt} . \%$ at the reduction temperature of $1073 \mathrm{~K}, 15.0 \mathrm{wt} . \%$ at $1123 \mathrm{~K}$, and $7.5 \mathrm{wt} . \%$ at $1173 \mathrm{~K}$. In addition, the oxygen concentration was $5.2 \mathrm{wt} . \%$ even at the highest reduction temperature of $1223 \mathrm{~K}$, confirming that all the samples contained high oxygen concentrations. Nevertheless, no oxide phase was observed in the X-ray diffraction, probably because a large amount of oxygen combined with metallic niobium as an amorphous form. Therefore, observation using a transmission electron microscope (TEM) was required.

Figure 8 shows the TEM structure and diffraction pattern analysis results of the $\mathrm{Nb}$ powder reduced at $1173 \mathrm{~K}$ as a representative case. In Fig. 8(a), several coarse $\mathrm{Nb}$ particles and ultrafine particles of several tens of nanometers or less were observed together while showing about a half and half amount in volume fraction. These ultrafine particles had extremely high specific surface areas. Therefore, likely to cause high oxygen concentrations by the formation of a large amount of passive film as shown in Fig. 8(b). Figure 8(c) shows the electron diffraction pattern of the area that contains
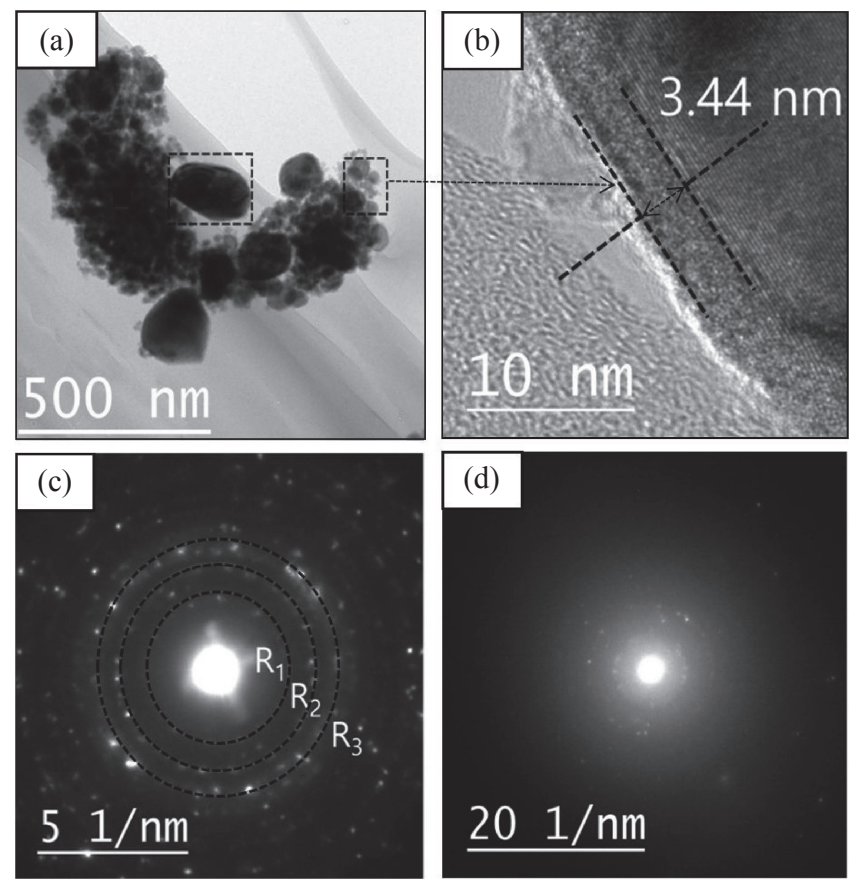

Fig. 8 TEM images (a), (b) and diffraction patterns (c), (d) of Mg-reduced $\mathrm{Nb}$ powder at $1173 \mathrm{~K}$ for $20 \mathrm{~h}$ after acid leaching.
Table 1 Comparison of the values $h^{2}+k^{2}+l^{2}$ and result found from ring diameters of diffraction patterns.

\begin{tabular}{cccc}
\hline & \multicolumn{3}{c}{ Diameters of } \\
Crystal Phases $(\mathrm{h}, \mathrm{k}, \mathrm{l})$ & $h^{2}+k^{2}+l^{2}$ & Diffraction & $\mathrm{R}_{i}{ }^{2}$ \\
& & Pattern, $\mathrm{R}_{i}$ & \\
\hline$\{110\}$ & 2 & $\mathrm{R}_{1}=4.552$ & 20.721 \\
$\{200\}$ & 4 & $\mathrm{R}_{2}=6.492$ & 42.146 \\
$\{211\}$ & 6 & $\mathrm{R}_{3}=7.923$ & 62.774 \\
\hline
\end{tabular}

relatively large particles. Diffraction spots caused by diffraction on the crystalline phase are visible, and a ring pattern is evident, a result of the diffraction by particle refinement with different crystal orientations. The relationships between the square of the diameter of the ring $\left(\mathrm{R} i^{2}\right)$ and the reciprocals of the squares of the distances between the diffractive surfaces (110), (200), and (211) $\left(\mathrm{a}^{2} / \mathrm{d}^{2}=h^{2}+\right.$ $k^{2}+l^{2}$, where a $=$ lattice parameter ${ }^{20)}$ and $\mathrm{d}=$ lattice plane spacing) were found to be 2:4:6 (see Table 1). These results reconfirmed the $\mathrm{Nb}$ phase with the $\mathrm{BCC}$ structure. Figure $8(d)$ shows the pattern of the fine particles. Diffraction spots caused by the crystalline phase were partially observed, and the halo ring pattern caused by the amorphous region was also confirmed. This was likely caused by the presence of fine particles and amorphous passive film.

It can be assumed that the detected oxygen has probably originated from not only the surface film but also internal core of niobium and such tendency is different according to the degree of particle refinements with different reduction temperatures.

Firstly, it was tried to measure the lattice constants from magnified XRD profiles because the lattice constant of core niobium can be influenced by lattice stress caused from 1) surface film or 2) solute such as oxygen concentration, normally oxygen. And we found there was no difference as the lattice constants had almost same values inside the range of $0.3303 \sim 0.3308 \mathrm{~nm}$ regardless of reduction temperatures.

It was reported the lattice constant of metallic nanoparticles can be decreased or increased by the effect of compress or tensile distortion of lattices, which can be originated from the characteristics of formed surface oxide film and such effects were shown usually below $10 \mathrm{~nm}$ of the crystal size by Scherrer equation. ${ }^{21,22)}$ On the other hand, as our Scherrer sizes were measured to be enough large, $25 \sim 35 \mathrm{~nm}$ as mentioned above, it was suggested in this study that such film effect on core lattice constants was probably negligible. Thus it can be explained the reason of nearly no-different lattice constants shown in this study.

Considering oxygen concentration secondly, it was reported that maximum oxygen solubility in niobium is nearly constant value of about $0.3 \mathrm{wt} . \%$ in ranges of $1173 \mathrm{~K}$ $1273 \mathrm{~K}^{23)}$ Therefore, the oxygen contents inside the coreniobium in this study probably were kept by a minimal value below $0.3 \mathrm{wt}$. $\%$ during reduction process because the driving force of $\mathrm{Mg}$-reduction was being operated. And the oxide 
film shown in Fig. 8(b) is obviously formed not during reduction but by air-exposal at room temperature after chemical washing. Hence we believed that the high oxygen contents shown in produced niobium powders were originated dominantly from not core niobium but surface film. And it has been reported that the lattice parameter of $\mathrm{NbO}_{0.017}$ phase, which is corresponded with about $0.3 \mathrm{wt} . \%$ oxygen, was $0.3305 \mathrm{~nm}^{24)}$ And we knew this value was well matched with our lattice constants of $0.3303 \sim 0.3308 \mathrm{~nm}$ as above mentioned.

It was required to improve the purity of the produced niobium by decrease the oxygen concentration of the reduced powder. And we considered that it can be accomplished by coarsening of the reduced particles by means of further increasing the reduction temperature or time.

As the operation was difficult above reduction temperatures of $1223 \mathrm{~K}$ because of the rapid vaporization of magnesium, an additional reduction experiment was performed, in which the reduction time was increased to $80 \mathrm{~h}$ and the reduction temperature was fixed at $1173 \mathrm{~K}$. Figure 9 shows the SEM results of this experiment. As expected, appearance of the fine particles decreased as the reduction time increased. Overall, the particles that were formed were approximately $1-2 \mu \mathrm{m}$. Figure 10 shows that an oxygen concentration of $7.5 \mathrm{wt} . \%$, obtained by a reduction over $20 \mathrm{~h}$, decreased to approximately $0.42 \mathrm{wt} . \%$ after a reduction for up to $60 \mathrm{~h}$ because of the particle growth effect.

Finally, to obtain pure metallic $\mathrm{Nb}$ powder, it was necessary to apply dehydrogenation heat treatment to the niobium hydride that was mixed in the produced powder. It has been reported that the temperature at which niobium hydride is dehydrogenated to metallic $\mathrm{Nb}$ is approximately $763 \mathrm{~K}$ for the vacuum condition. ${ }^{25,26)}$ In this study, dehydrogenation heat treatment was performed at a higher

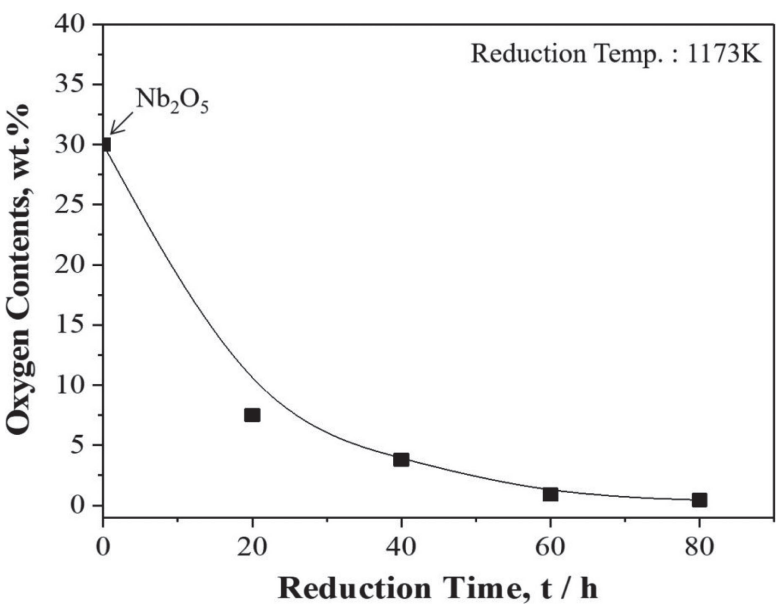

Fig. 10 Oxygen contents of Mg-reduced $\mathrm{Nb}$ powder, depending on different reduction times.

temperature of $973 \mathrm{~K}$ for $2 \mathrm{~h}$ under a vacuum condition of $6 \times 10^{-6} \mathrm{kPa}$.

Figure 11 shows the X-ray diffraction analysis results of the $\mathrm{Nb}$ powder reduced at $1173 \mathrm{~K}$ for $60 \mathrm{~h}$ before and after the dehydrogenation heat treatment. The $\mathrm{NbH}$ phase was not visible after the dehydrogenation treatment, confirming that the hydrogen was removed. The elemental analyzer also confirmed that hydrogen was not present. After the dehydrogenation heat treatment, the morphology and size of the final metallic $\mathrm{Nb}$ powder were similar to those in Fig. 9(c). The oxygen concentration was measured to 0.41 wt. $\%$ a little smaller than the value before the dehydrogenation treatment. And such decreasing effect of oxygen content by dehydrogenation can be suggested by the additional reduction effect by de-gassed hydrogen atoms ${ }^{18)}$ and it is being more studied.
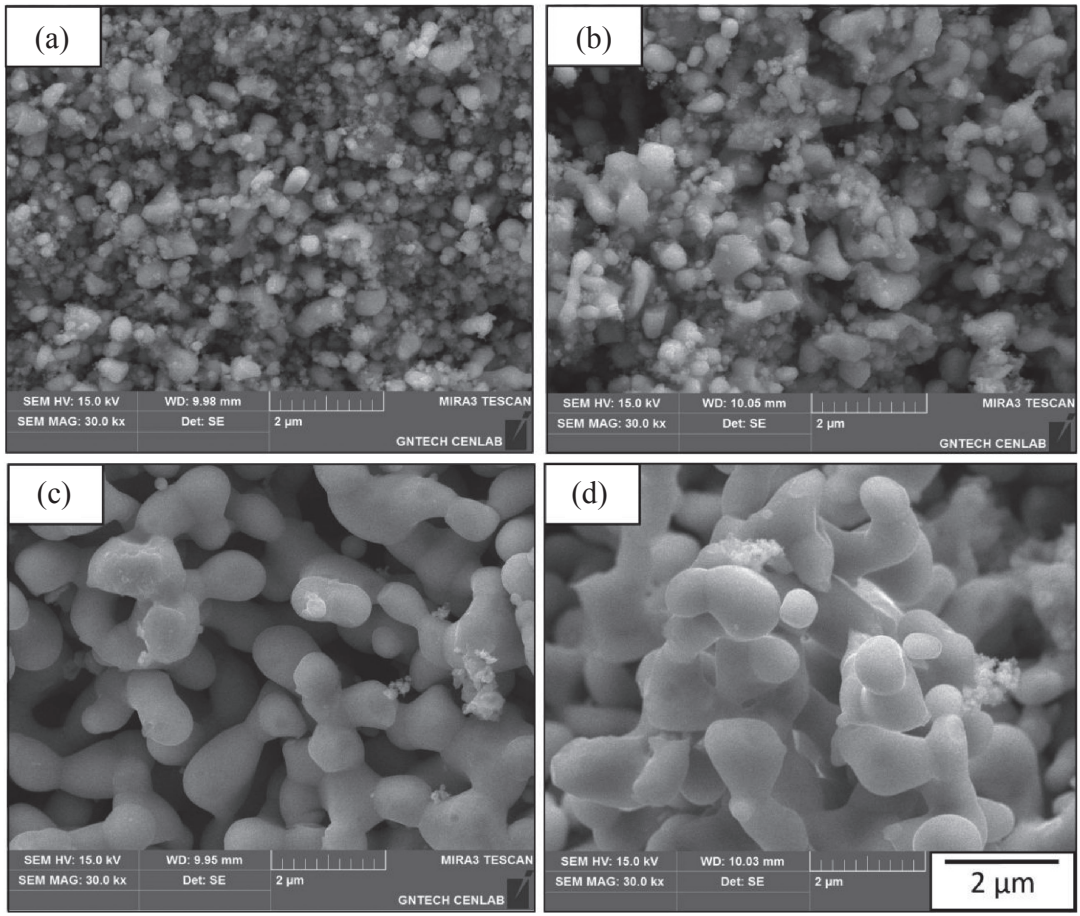

Fig. 9 SEM microstructures of samples of $\mathrm{Nb}$ powder that were Mg-reduced at $1173 \mathrm{~K}$ and acid-leached for different reduction times:

(a) $20 \mathrm{~h}$, (b) $30 \mathrm{~h}$, (c) $60 \mathrm{~h}$, and (d) $85 \mathrm{~h}$. 


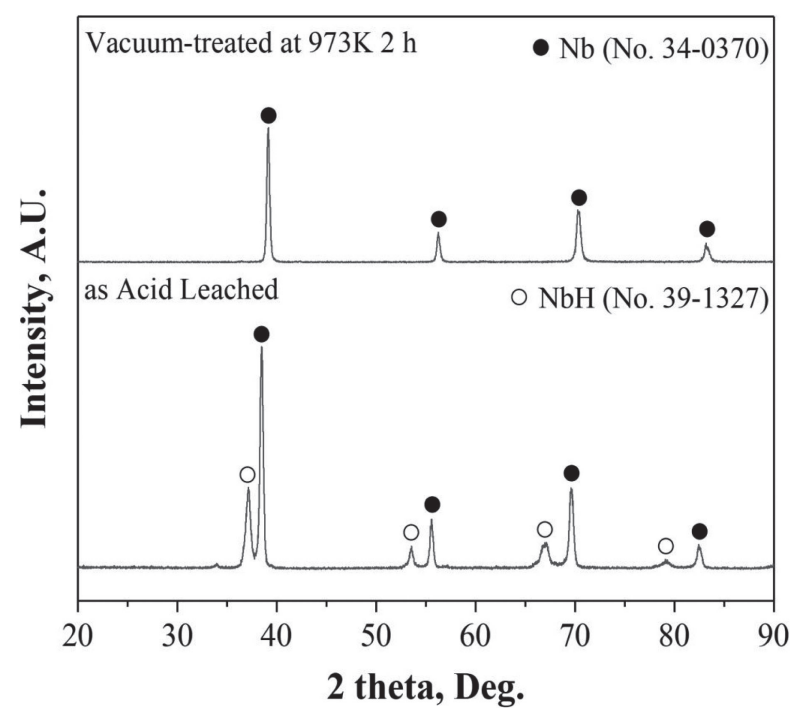

Fig. 11 XRD of the sample reduced at $1173 \mathrm{~K}$ for $60 \mathrm{~h}$, before and after vacuum heat treatment at $973 \mathrm{~K}$ for $2 \mathrm{~h}$.

It was accomplished in this study to find the optimal oxygen conditions on the magnesium gas reduction with pure $\mathrm{Nb}_{2} \mathrm{O}_{5}$ powders under the atmospheric chamber pressure. By obtained results, the industrial research work is being continued with chamber design for the capacity of $100 \mathrm{~kg}$ batch.

\section{Conclusion}

In this study, we successfully produced pure niobium powder, using niobium oxide as the initial compound through a reduction reaction with gaseous magnesium of atmospheric pressure. Initially, when we analyzed the SEM images of the powder samples reduced at temperatures between $1073 \mathrm{~K}$ and $1223 \mathrm{~K}$ for $20 \mathrm{~h}$, we found that the particle size ranged from $200-600 \mathrm{~nm}$ and the internal crystal size of each particle ranged from $25-35 \mathrm{~nm}$. As we investigated the TEM structure, owing to the ultrafine particles and the passive film, a high oxygen concentration of $7 \mathrm{wt} \%$ or more was present. The reduction time was increased to $80 \mathrm{~h}$ to decrease the concentration of oxygen, as it was an impurity. The ultrafine particles that had been observed after the reduction for $20 \mathrm{~h}$ were efficiently removed, and the particles grew to sizes of $1 \sim 2 \mu \mathrm{m}$. In this process, the oxygen concentration was reduced to $0.42 \mathrm{wt} . \%$. In the obtained niobium powder, we measured the mixed niobium hydride phases to be about 20 45 wt. \%, depending on the temperature. Finally, we obtained approximately $99.6 \%$ pure metallic $\mathrm{Nb}$ powder by performing a dehydrogenation heat treatment at $873 \mathrm{~K}$ under a vacuum condition to remove the hydrogen from $\mathrm{NbH}$.

\section{Acknowledgments}

This study was supported by the Research Program (PNK7190) of the Korea Institute of Materials Science (KIMS), Republic of Korea.

\section{REFERENCES}

1) J.S. Yoon, J.Y. Yang, J.M. Lee and S.J. Hong: Mater. Trans. 54 (2013) $114-118$.

2) D.J. Soisson: Ind. Eng. Chem. 53 (1961) 861-868.

3) M. Baba, T. Kikuchi and R.O. Suzuki: J. Phys. Chem. Solids 78 (2015) 101-109.

4) M. Baba, Y. Ono and R.O. Suzuki: J. Phys. Chem. Solids 66 (2005) $466-470$.

5) J.S. Yoon: Int. J. Refract. Met. Hard Mater. 28 (2010) 265-269.

6) N. Wang, K. Huang, J. Hou and H. Zhu: Rare Met. 31 (2012) 621.

7) C.P. De Lazzari, D.G. Simões and J.D.T. Capocchi: Mater. Res. 10 (2007) 215-218.

8) J.M. Juneja: High Temp. Mater. Proc. 24 (2005) 1-6.

9) A. Awasthi, Y.J. Bhatt, N. Krishnamurthy, Y. Ueda and S.P. Garg: J. Alloy. Compd. 315 (2001) 187-192.

10) M. Jafari, H. Tajizadegan, M.H. Golabgir, A. Chami and O. Torabi: Int. J. Refract. Met. Hard Mater. 50 (2015) 86-92.

11) S. Luidold, H. Antrekowitsch and R. Ressel: Int. J. Refract. Met. Hard Mater. 25 (2007) 423-432.

12) I. Park, T.H. Okabe, Y. Waseda, H.S. Yu and O.Y. Lee: Mater. Trans. 42 (2001) 850-855.

13) D.W. Lee, S.H. Heo, J.T. Yeom and J.P. Wang: J. Kor. Powd. Met. Inst. 20 (2013) 43-47.

14) S.M. Hwang, J.P. Wang and D.W. Lee: Metals 9 (2019) 5-13.

15) T.H. Okabe, S. Iwata, M. Imagunbai and M. Maeda: ISIJ Int. 43 (2003) 1882-1889.

16) V.M. Orlov, M.V. Kryzhanov and V.T. Kalinnikov: Dokl. Chem. 465 (2015) 257-260.

17) T.S. Kumar, S.R. Kumar, M.L. Rao and T.L. Prakash: J. Met. 2013 (2013) 629341.

18) D.W. Lee, H.S. Lee, J.H. Park, S.M. Shin and J.P. Wang: Procedia Manufacturing 2 (2015) 550-557.

19) M.A.R. Miranda and J.M. Sasaki: Acta Crystallogr. Sec. A 74 (2018) 54-65.

20) R. Roberge: J. Less Common Met. 40 (1975) 161-164.

21) R. Banerjee, E.A. Sperling, G.B. Thompson and H.L. Fraser: Appl. Phys. Lett. 82 (2003) 4250-4252.

22) B.G. Kelly, A.B. Loether, A.D. DiChiara, R.W. Henning, M.F DeCamp and K.M. Unruh: J. Phys. Chem. Solids 108 (2017) 104-108.

23) O.P. Kolchin and N.V. Sumarokova: Soviet Atomic Energy 45 (1978) 999-1001.

24) M.E. Straumanis and S. Zyszczynski: J. Appl. Crystallogr. 3 (1970) 16.

25) S.B. Gabriel, M.C. Brum, K.C.G. Candioto, H.R.Z. Sandim, P.A. Suzuki and C.A. Nunes: Int. J. Refract. Met. Hard Mater. 30 (2012) 38 41.

26) J.J. Reilly and R.H. Wiswall, Jr.: Inorg. Chem. 9 (1970) 1678-1682. 